\title{
A Stacked Microstrip Antenna Array with Fractal Patches
}

\author{
Xueyao Ren, Xing Chen, Yufeng Liu, Wei Jin, and Kama Huang \\ College of Electronics and Information, Sichuan University, Chengdu 610064, China \\ Correspondence should be addressed to Xing Chen; chenxingscu@163.com
}

Received 22 October 2013; Revised 26 November 2013; Accepted 16 December 2013; Published 9 February 2014

Academic Editor: Xiuping Li

Copyright (C) 2014 Xueyao Ren et al. This is an open access article distributed under the Creative Commons Attribution License, which permits unrestricted use, distribution, and reproduction in any medium, provided the original work is properly cited.

\begin{abstract}
A novel microstrip antenna array, which utilizes Giuseppe Peano fractal shaped patches as its radiation elements and adopts a two-layer stacked structure for achieving both wideband and high-gain properties, is proposed. Parametric study estimates that the proposed antenna's size can be arbitrarily adjusted by changing the fractal proportion while high aperture efficiency is maintained. Two prototypes with $2 \times 2$ and $4 \times 4$ fractal patches, respectively, on each layer are designed, fabricated, and measured. Both simulation and measurement results demonstrate that the proposed antenna possesses encouraging performances of wideband, high directivity, and high aperture efficiency simultaneously; for example, for the two prototypes, their $S_{11}<-10 \mathrm{~dB}$ impedance bandwidths are $23.49 \%$ and $18.49 \%$, respectively; at the working frequency of $5.8 \mathrm{GHz}$, their directivities are $12.2 \mathrm{dBi}$ and $18.2 \mathrm{dBi}$, and their corresponding aperture efficiencies are up to $91.0 \%$ and $90.5 \%$, respectively.
\end{abstract}

\section{Introduction}

Directional antennas with high radiation gain are key devices in many practical applications such as the remote wireless communication. Due to their attractive features like low weight, low profile, small size, and being easy to manufacture, employing microstrip antennas to form array is a widely adopted method to design directional antennas with high gain. However, it is well known that microstrip antennas have an intrinsically narrow bandwidth [1], typically a small percent of the center frequency. In view of the explosive growth of the wireless system and the booming demand for a variety of new wireless applications, it is important to design directional antennas with both wideband and high gain to cover a wide frequency range. Indeed, there are countless researches proposed in the literature to design microstrip antennas with high gain or wide bandwidth, but few of them are for both properties together.

To tackle the narrow bandwidth problem of microstrip antennas, various techniques have been proposed. Among them is stacking one or several parasitic layers on a microstrip antenna [2], and various methods have been widely used. For example, the 8-layer stacked patch unit assembly allows for great bandwidth which is more than $50 \%$ of the center frequency [3] and the use of high dielectric constant substrate for the driven layer and low dielectric constant substrate for the superstrate can offer more than $25 \%$ on bandwidth $[4,5]$. The intrinsic properties of fractal geometries are conducive to the miniaturization of antenna size and realization of multiband or broadband characteristics [6,7]; L-shape slot loaded broadband patch antenna for enhancing the gain without affecting the broadband impedance matching characteristics [8]; the artificial magnetic conductor structures are employed as the antenna magnetic ground plane for bandwidth enhancement and radiation gain improvement of patch antenna [9]. A dipole antenna with a double electromagnetic band gap (EBG) reflector is presented for wide operating bandwidth and high gain [10]. However, there are some defects in the designs. Some of them have high profile; some of them require special materials and increase the production costs; some of them have complex structures, which increase the difficulty in manufacture. More details are shown in Table 1.

In this work, a novel microstrip antenna array, which employs a two-layer stacked structure and Giuseppe Peano fractal shaped patches for realizing both wideband and high gain properties, is proposed, analyzed, and measured. The remainder of the paper is organized as follows. Section 2 introduces the configuration of the proposed antenna array. A parametric study is presented in Section 3. Simulated and 
TABle 1: Detailed data of the antennas mentioned previously.

\begin{tabular}{lccccccc}
\hline Literature number & Number of layer & Number of array elements & Gain (dBi) & Bandwidth & Profile & Manufacture difficulty & Cost \\
\hline$[3]$ & 8 & 1 & 7.4 & $52 \%$ & High & Hard & High \\
{$[4]$} & 2 & 4 & 12.4 & $25.6 \%$ & Low & Easy & High \\
{$[5]$} & 2 & 1 & - & $35 \%$ & Low & Easy & High \\
{$[8]$} & 2 & 1 & 8.3 & $20 \%$ & Low & Easy & Low \\
{$[9]$} & 4 & 4 & 15.95 & $20.45 \%$ & High & Hard & High \\
{$[10]$} & 4 & 1 & 8.5 & $44.4 \%$ & High & Easy & Low \\
\hline
\end{tabular}

measured properties of two prototypes with $2 \times 2$ and $4 \times$ 4 fractal patches, respectively, on each layer are given in Section 4. Conclusions are stated in Section 5.

\section{Antenna Configuration}

Fractals are geometrical shapes, which are self-similar, repeating themselves at different scales. With the development of the fractal theory, the nature of fractal geometries has been exploited in many fields of engineering and science, including antenna design. The utilization of fractal geometries in antenna design has led to the evolution of a new class of antennas called fractal shaped antennas.

The Giuseppe Peano fractal is a class of fractal geometries. Its recursive procedure is shown in Figure 1. A Giuseppe Peano starts from a segment with length $f_{2}$ and allows its central part with length $f_{1}$ to break into two zigzag sections; it is constructed iteratively by growing new zigzag sections that have a specific length ratio $n=f_{2} / f_{1}$ with respect to their parent section.

As depicted in Figure 2, when the Giuseppe Peano fractal is applied to the edges of the square patch, this fractal patch with different sections resonates at different frequencies which together to form a wide working frequency band.

The configuration of the proposed microstrip antenna array is illustrated in Figure 3. This antenna utilizes a twolayer stacked structure, containing a radiation layer and a parasitic layer. Each layer is printed on a PCB (printed circuit board) with relative permittivity $\varepsilon_{r}=2.55$ and thickness $h=1 \mathrm{~mm}$. The two layers are separated by air with distance of $h_{z}=3.2 \mathrm{~mm}$.

On the top surface of the radiation layer, some Giuseppe Peano fractal shaped patches are etched periodically. They act as radiators and are connected to a microstrip corporate feeding network to form an array. On the bottom surface of the parasitic layer, the same patches as that on the radiation layer are also etched. Those patches are parasitic elements for enhancing the bandwidth and gain of the antenna array.

This antenna is fed from a $50 \Omega$ coaxial connector. The microstrip corporate feeding network consists of a serial of $T$-junctions to deliver electromagnetic energy uniformly and multiple-section quarter-wavelength impedance transformers to achieve impedance match and is used to provide equal amplitude and in-phase excitation to all fractal shaped patches.

From Figure 3, we can see that $L s=2 \times(D+L), X=$ $(D-L 0-W 1) / 2 L t=(D+L-W 2) / 2$, and $L 3=(D+L)-$
$2 \times(L 1+L 2)-W 1$. Finally, the structural parameters of this antenna are optimized by Genetic Algorithm (GA) [11, 12] as follows: $D=16.46 \mathrm{~mm}, L=14.71 \mathrm{~mm}, \mathrm{Lr}=16.06 \mathrm{~mm}$, $W 1=2.27 \mathrm{~mm}, W 2=2.07 \mathrm{~mm}, W 3=1.77 \mathrm{~mm}, L 0=$ $1.38 \mathrm{~mm}, L 1=3.66 \mathrm{~mm}, L 2=8.20 \mathrm{~mm}$, and $h_{z}=3.19 \mathrm{~mm}$. The total area of the antenna is $62.34 \times 62.34 \mathrm{~mm}^{2}$.

\section{Parametric Study}

Here, we investigate the effect of the antenna's parameters on its performance characteristics. In this section, the proposed antenna works at $5.8 \mathrm{GHz}$, has $2 \times 2$ and fractal $4 \times 4$ patches on the radiation and parasitic layers, respectively, and adopts second iteration Giuseppe Peano fractal patches.

3.1. Effect of the Fractal Proportion. The Fractal proportion $n$ is defined as

$$
n=\frac{f_{2}}{f_{1}},
$$

which can be seen from Figure 1. The greater the $n$ is, the closer to square patch the Peano fractal radiator is.

The $2 \times 2$ square patches antenna array which works at the same frequency of $5.8 \mathrm{GHz}$ is illustrated in Figure 4 . Each layer is printed on a PCB with relative permittivity $\varepsilon_{r}=2.55$ and thickness $h=1 \mathrm{~mm}$, the same as the fractal ones.

The structural parameters of this antenna which is optimized by GA are as follows: $D=29.50 \mathrm{~mm}, L=15.02 \mathrm{~mm}$, $L r=17.30 \mathrm{~mm}, W 1=3.72 \mathrm{~mm}, W 2=2.78 \mathrm{~mm}$, $W 3=2.18 \mathrm{~mm}, L 0=1.52 \mathrm{~mm}, L 1=3.40 \mathrm{~mm}, L 2=$ $13.27 \mathrm{~mm}$, and $h_{z}=3.48 \mathrm{~mm}$. The simulated reflection coefficient and simulated directivity are given by Figures 5 and 6 , respectively.

It is obvious that the $S_{11}<-10 \mathrm{~dB}$ impedance bandwidth is about $14.02 \%$ (from $5.37 \mathrm{GHz}$ to $6.18 \mathrm{GHz}$ ). At its working frequency of $5.8 \mathrm{GHz}$, the antenna has an input reflection coefficient of $-22.65 \mathrm{~dB}$, which estimates that a good impedance match has been achieved.

Different $2 \times 2$ array antennas of different fractal proportion ( $n=2, n=2.5, n=3, n=3.5, n=4$, and $n=4.5)$ which are also working at $5.8 \mathrm{GHz}$ are optimized by GA. Figure 7 reveals the simulated reflection coefficient of different fractal proportion antenna arrays and Figure 8 reveals the simulated directivity.

From Table 2, one can observe that the fractal proportion has a great influence on the antenna performance. As fractal proportion $n$ increases, the aperture area of the proposed 


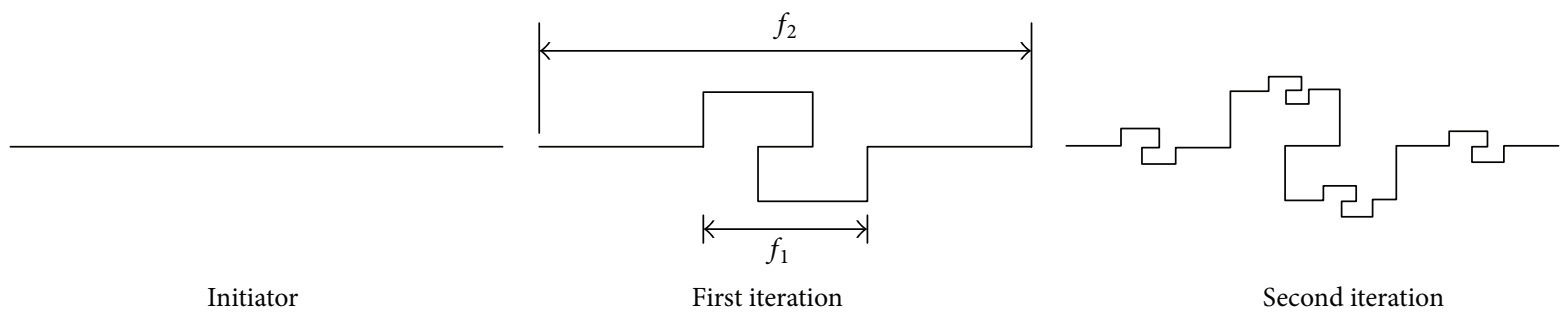

Figure 1: The recursive procedure of the Giuseppe Peano fractal.

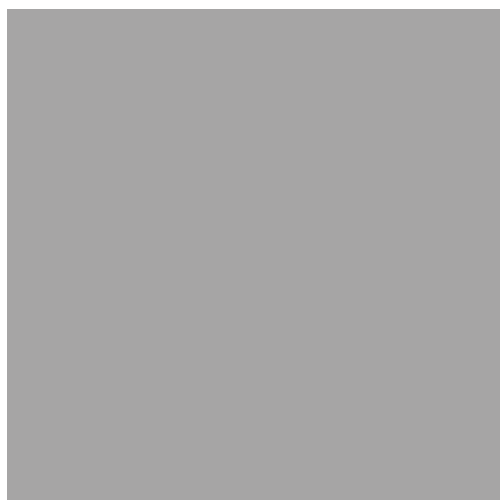

Initiator

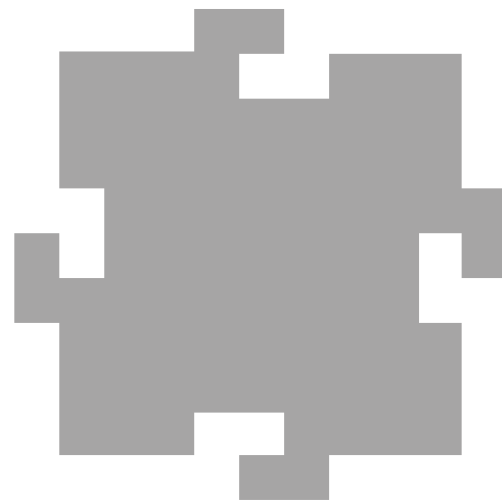

First iteration

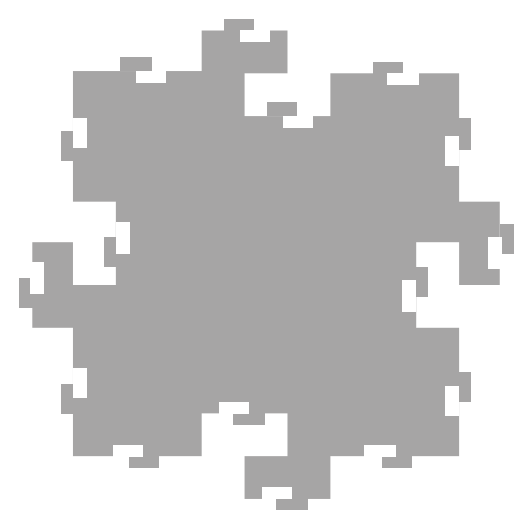

Second iteration

Figure 2: The Giuseppe Peano fractal patch.

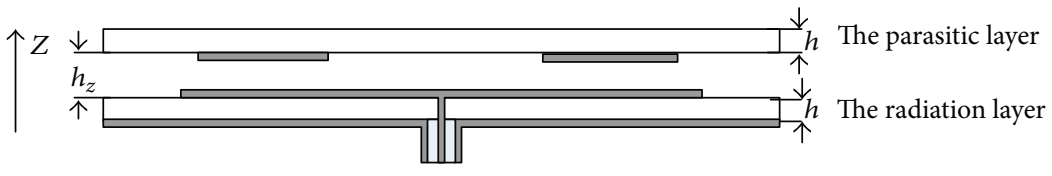

Metal

$\square$ Dielectric

(a) The cross-section diagram

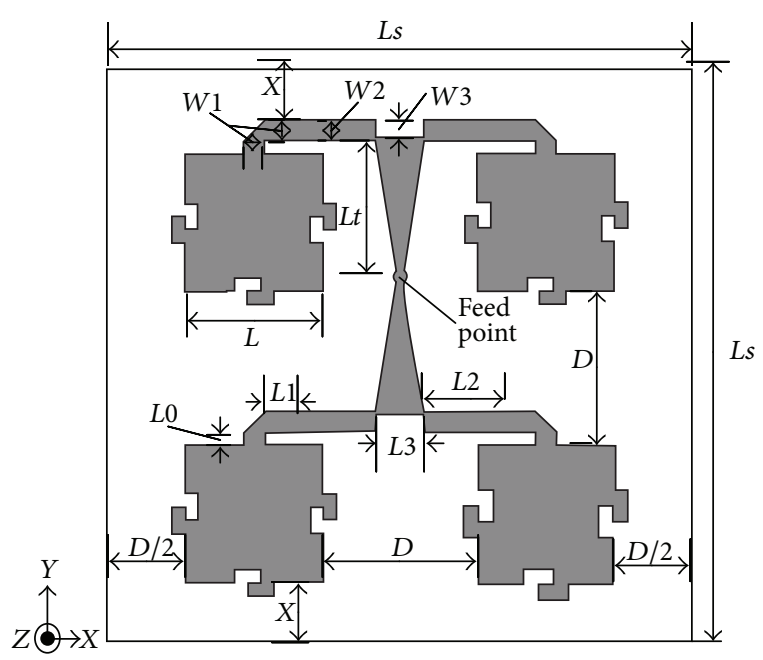

(b) The radiation layer

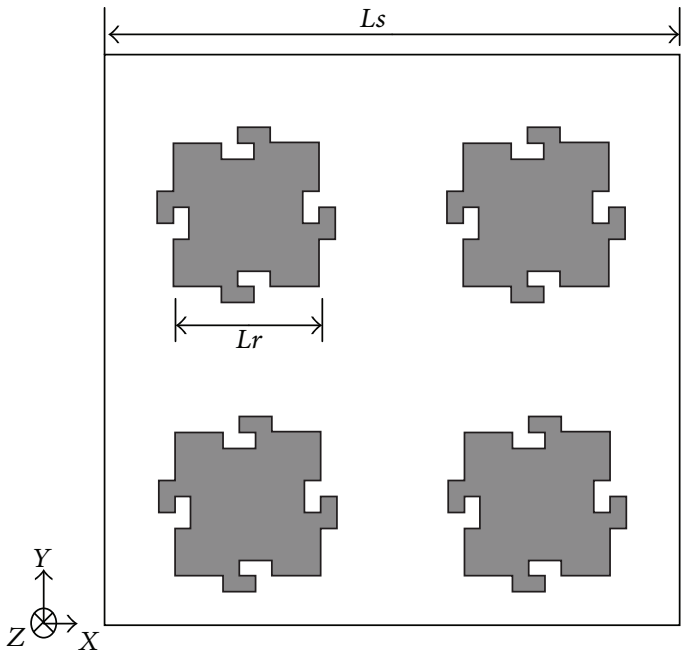

(c) The parasitic layer

FIGURE 3: Configuration of the proposed microstrip antenna array. 


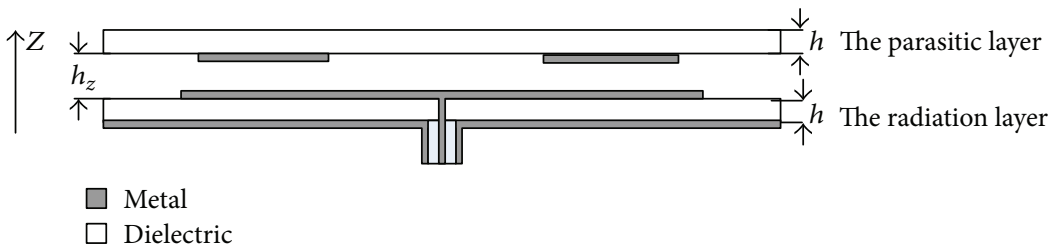

(a) The cross-section diagram

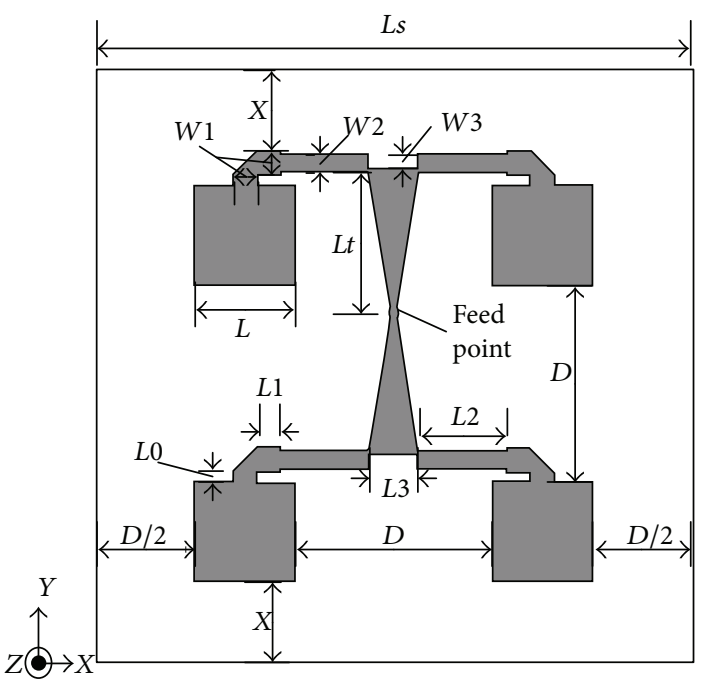

(b) The radiation layer

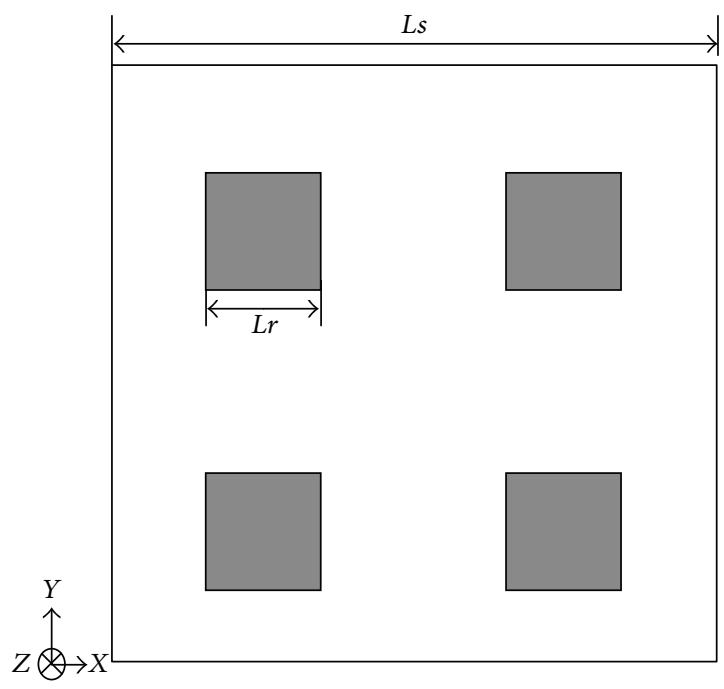

(c) The parasitic layer

FIgURE 4: The configuration of the two-layer square patches $2 \times 2$ antenna array.

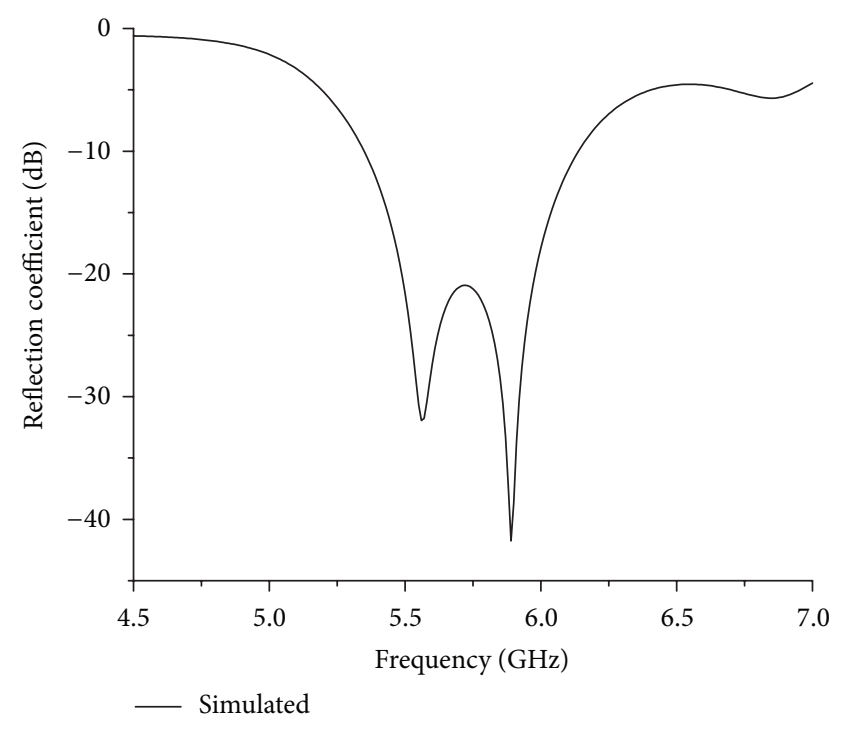

FIGURE 5: The simulated reflection coefficient of the square antenna array.

antenna must increase for maintaining the same working frequency of $5.8 \mathrm{GHz}$. When the fractal proportion $n=3.5$, the $S_{11}<-10 \mathrm{~dB}$ impendence bandwidth reaches $23.49 \%$ versus $14.02 \%$ of the square antenna array working at the same

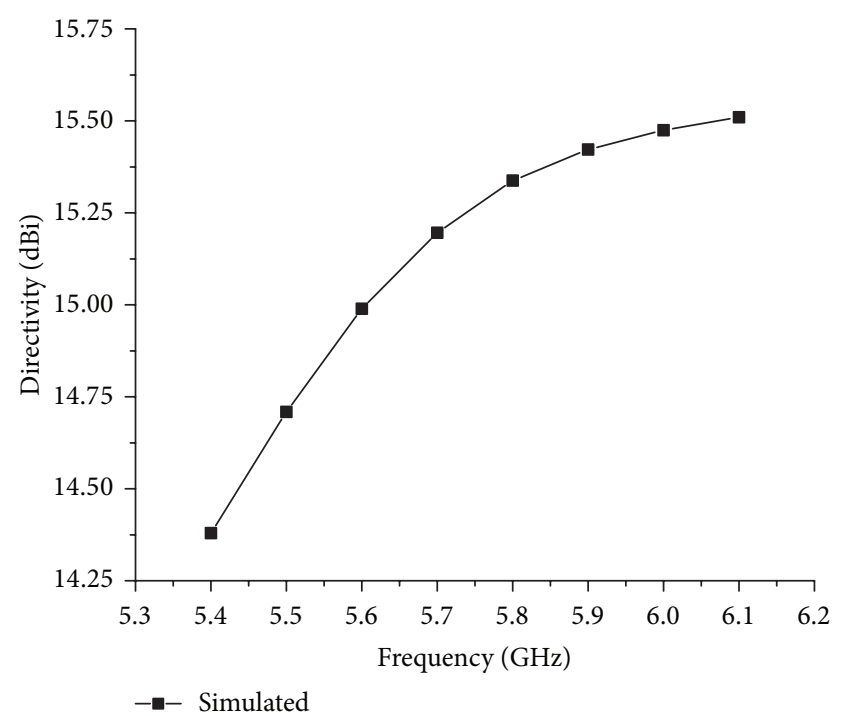

FIGURE 6: The simulated directivity as a function of frequency for the square patches antenna array.

frequency, the aperture area of proposed antenna is only $49 \%$ of the square patches antenna array's.

Another interesting observation worthwhile pointing out is the attainable aperture efficiency calculated only by the 


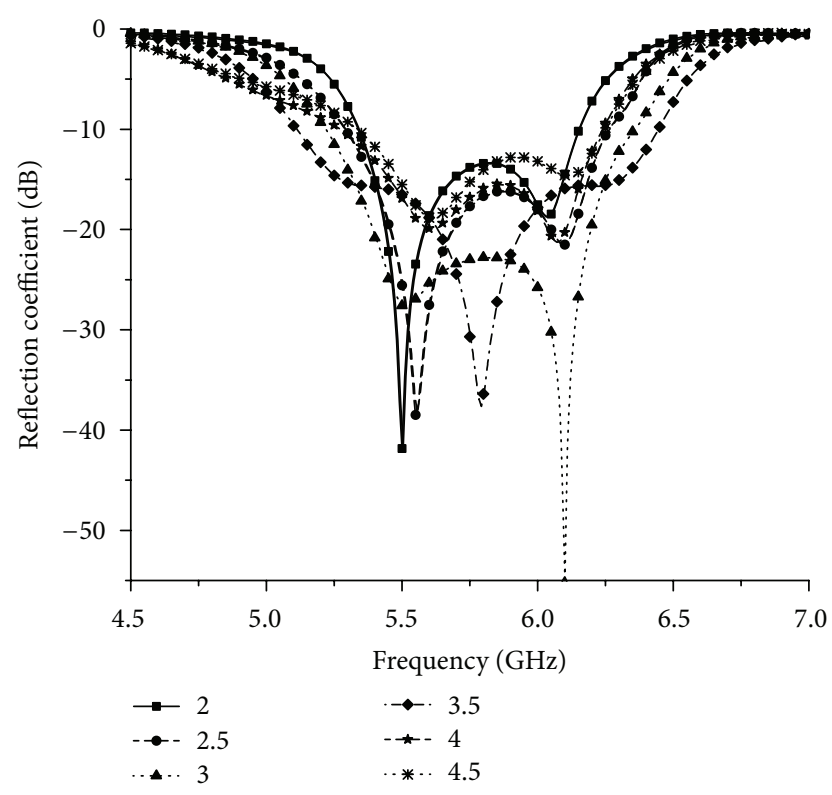

FIGURE 7: The simulated reflection coefficient of the different fractal proportion.

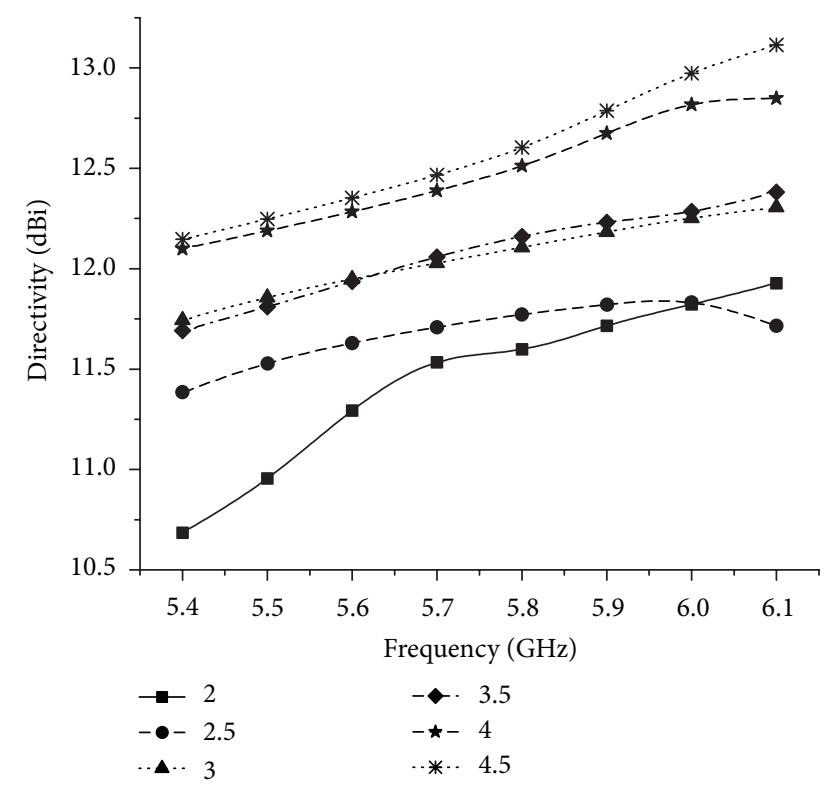

FIGURE 8: The simulated directivity as a function of frequency for the different fractal proportion.

directivity, shown in Figure 9. The vast majority of them are more than $85 \%$. The average aperture efficiency (from $5.4 \mathrm{GHz}$ to $6.1 \mathrm{GHz}$ ) is shown in Table 3 .

Table 3 demonstrates that the average aperture efficiency of the Peano fractal antenna array is higher than that of the square antenna in the same working band. The maximum value of average aperture efficiency is obtained when the fractal proportion $n=4$.

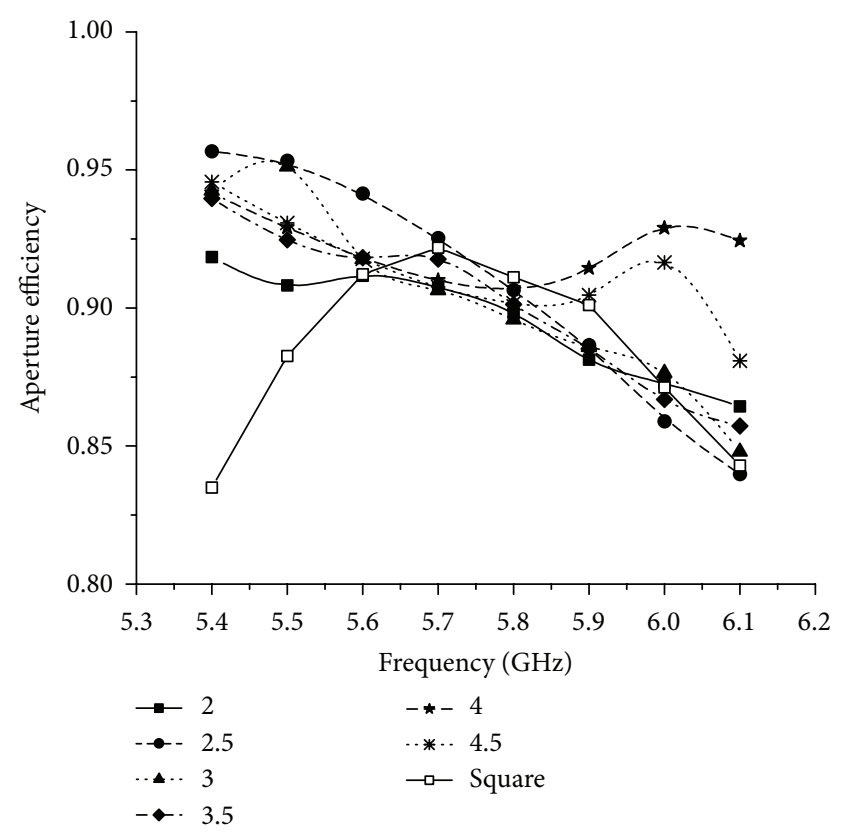

FIGURE 9: The simulated aperture efficiency of the different fractal proportion antenna array.

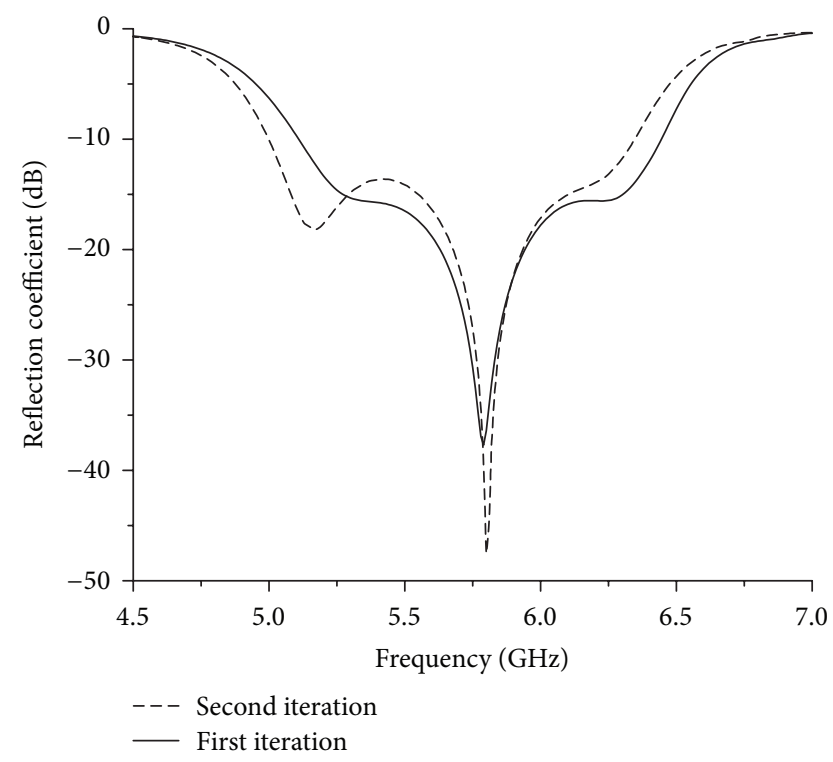

FIGURE 10: Comparison of the simulated reflection coefficient of the 1st iteration and 2nd iteration.

3.2. Effect of Fractal Iteration. First and second iteration are relatively applied to the edges of the square patch. All the parameters of the second iteration antenna array are set to be the same as the first one. The comparison of the reflection coefficient of these two antennas is drawn in Figure 10.

One can observe that the impedance bandwidth for $S_{11}<$ $-10 \mathrm{~dB}$ is $24.18 \%$ (from $4.98 \mathrm{GHz}$ to $6.35 \mathrm{GHz}$ ), which is much wider than that of square patches antenna array and slightly larger than that achieved in first iteration of the fractal patches antenna array. As the iteration of fractal geometry increases, 


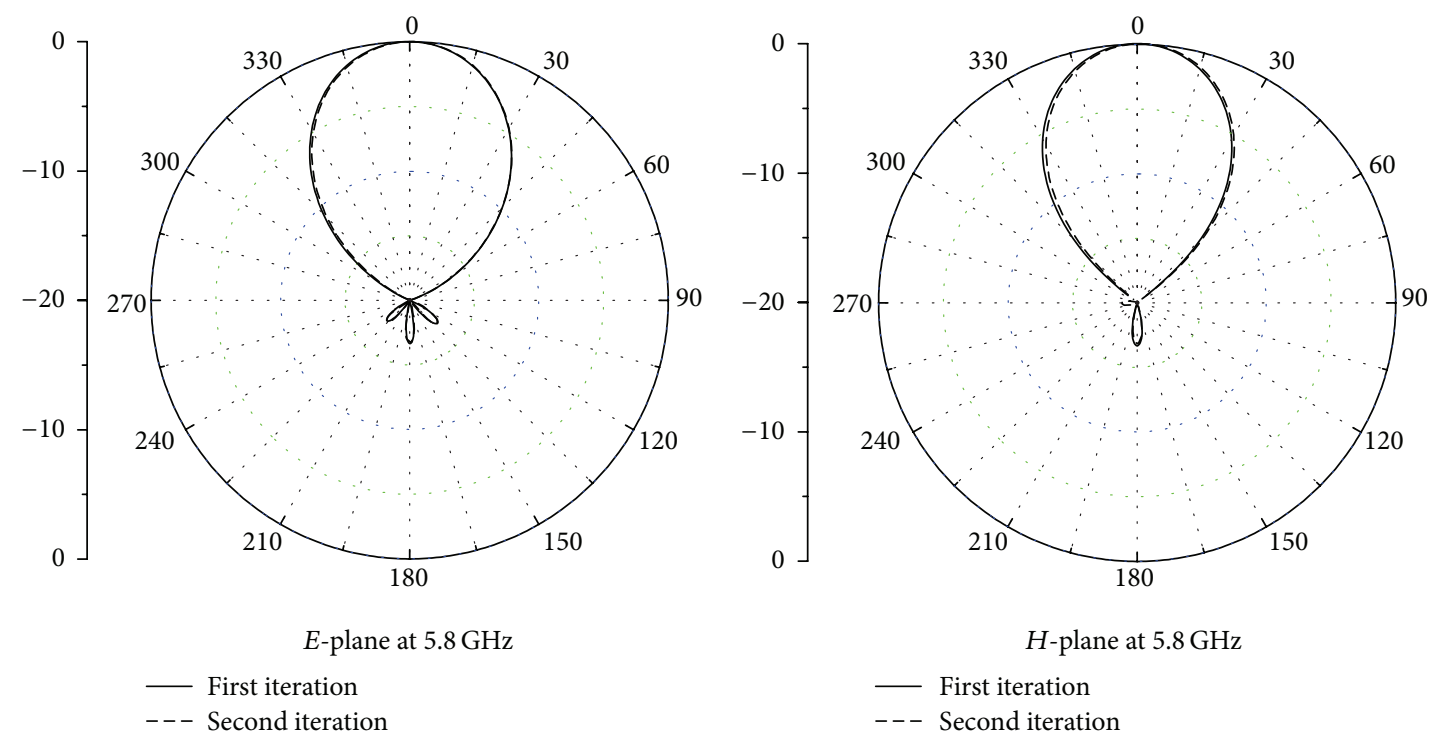

FIGURE 11: Comparison of the radiation patterns of the fractal iterations, 1st and 2nd.

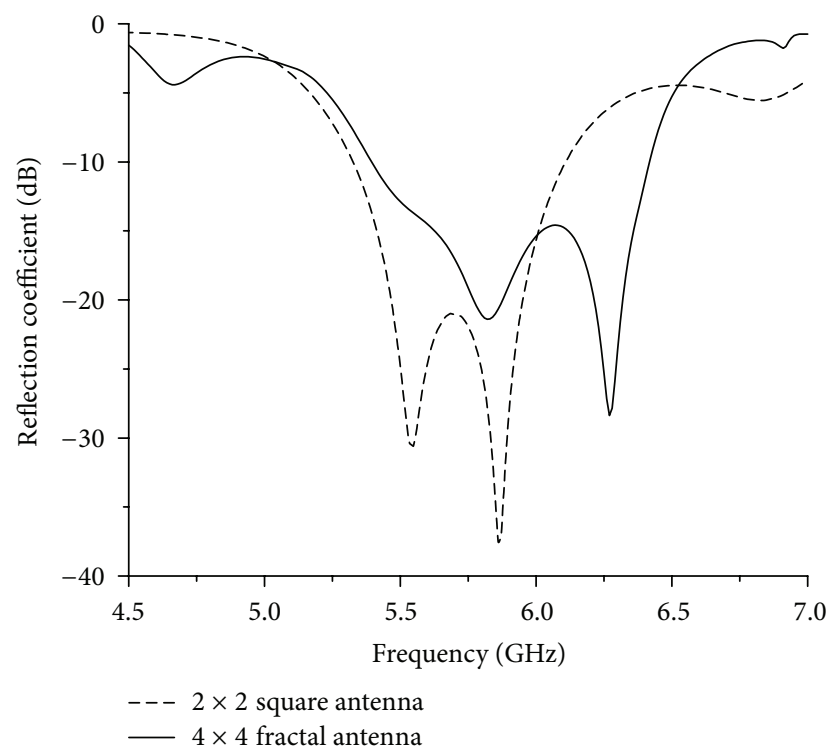

FIGURE 12: Comparison of the simulated reflection coefficient of the $2 \times 2$ square patch antenna and the $4 \times 4$ Giuseppe Peano fractal antenna.

its resonance frequency decreases, which may lead to an effective antenna miniaturization. However, for iterations higher than the second iteration, the antenna design becomes quite complicated and its fabrication becomes difficult. The comparison of simulated radiation patterns in the $E$-plane and $H$-plane of these two antennas is shown in Figure 11.

The comparison indicates that the influence of radiation patterns that comes from the fractal iteration is almost negligible.
TABLE 2: Details of different antennas.

\begin{tabular}{lccccc}
\hline$n$ & $f_{\mathrm{L}}(\mathrm{GHz})$ & $f_{\mathrm{H}}(\mathrm{GHz})$ & $f_{\mathrm{M}}(\mathrm{GHz})$ & $f_{\%}$ & $L_{\mathrm{s}}(\mathrm{cm})$ \\
\hline 2 & 5.33 & 6.23 & 5.78 & $15.57 \%$ & 56.68 \\
2.5 & 5.29 & 6.27 & 5.78 & $16.98 \%$ & 59.43 \\
3 & 5.21 & 6.37 & 5.79 & $20.03 \%$ & 62.12 \\
3.5 & 5.07 & 6.42 & 5.78 & $23.49 \%$ & 62.34 \\
4 & 5.28 & 6.30 & 5.79 & $17.62 \%$ & 64.90 \\
4.5 & 5.33 & 6.25 & 5.79 & $15.89 \%$ & 65.40 \\
Square & 5.37 & 6.18 & 5.78 & $14.02 \%$ & 89
\end{tabular}

Table 3

\begin{tabular}{lc}
\hline Fractal proportion $n$ & Average aperture efficiency \\
\hline 2 & $89.53 \%$ \\
2.5 & $90.86 \%$ \\
3 & $90.30 \%$ \\
3.5 & $91 \%$ \\
4 & $92.18 \%$ \\
4.5 & $91.32 \%$ \\
Square & $88.48 \%$ \\
\hline
\end{tabular}

3.3. Effect of Array Elements Number. In this part, a proposed antenna with $4 \times 4$ Giuseppe Peano fractal radiated elements and working at $5.8 \mathrm{GHz}$ is also optimized by GA.

Figure 12 compares the simulated reflection coefficient of the $2 \times 2$ square patch antenna and that of the $4 \times 4$ Giuseppe Peano fractal antenna. As known to all, when the number of array elements increases, the impedance bandwidth of the antenna array decreases because of the mutual coupling between the array elements $[13,14]$. Although the element number of fractal antenna array is four times that in the square antenna, the impedance bandwidth for $S_{11}<-10 \mathrm{~dB}$ 

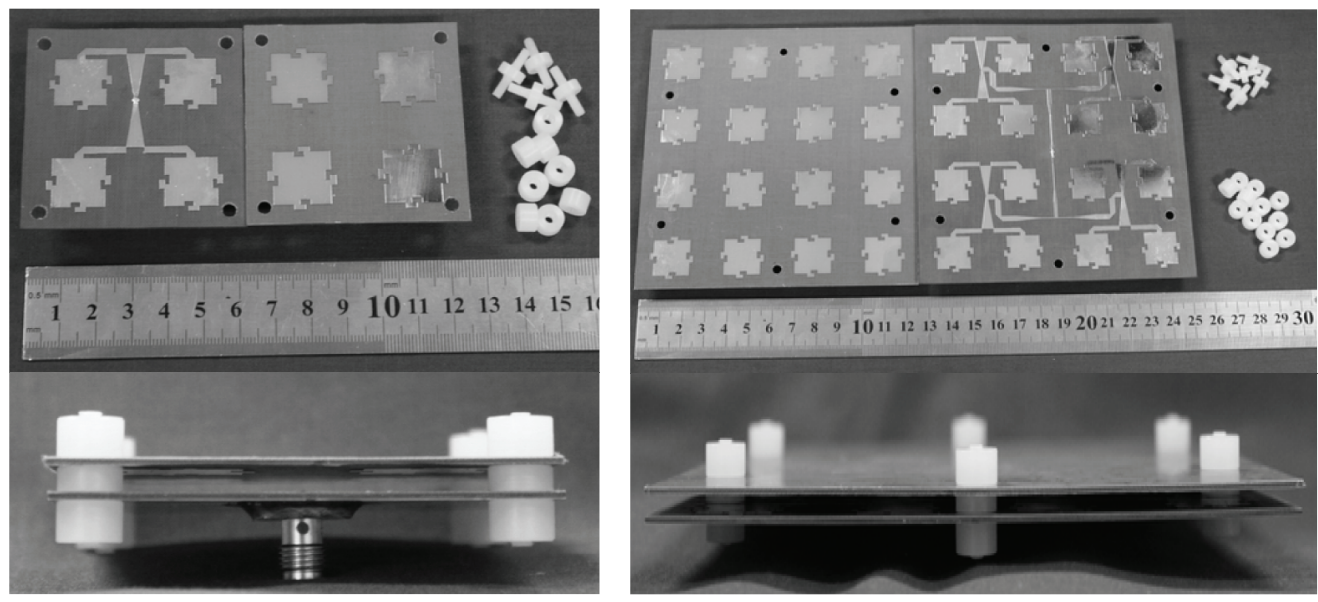

FIGURE 13: The both layers of the fabricated prototype antennas.
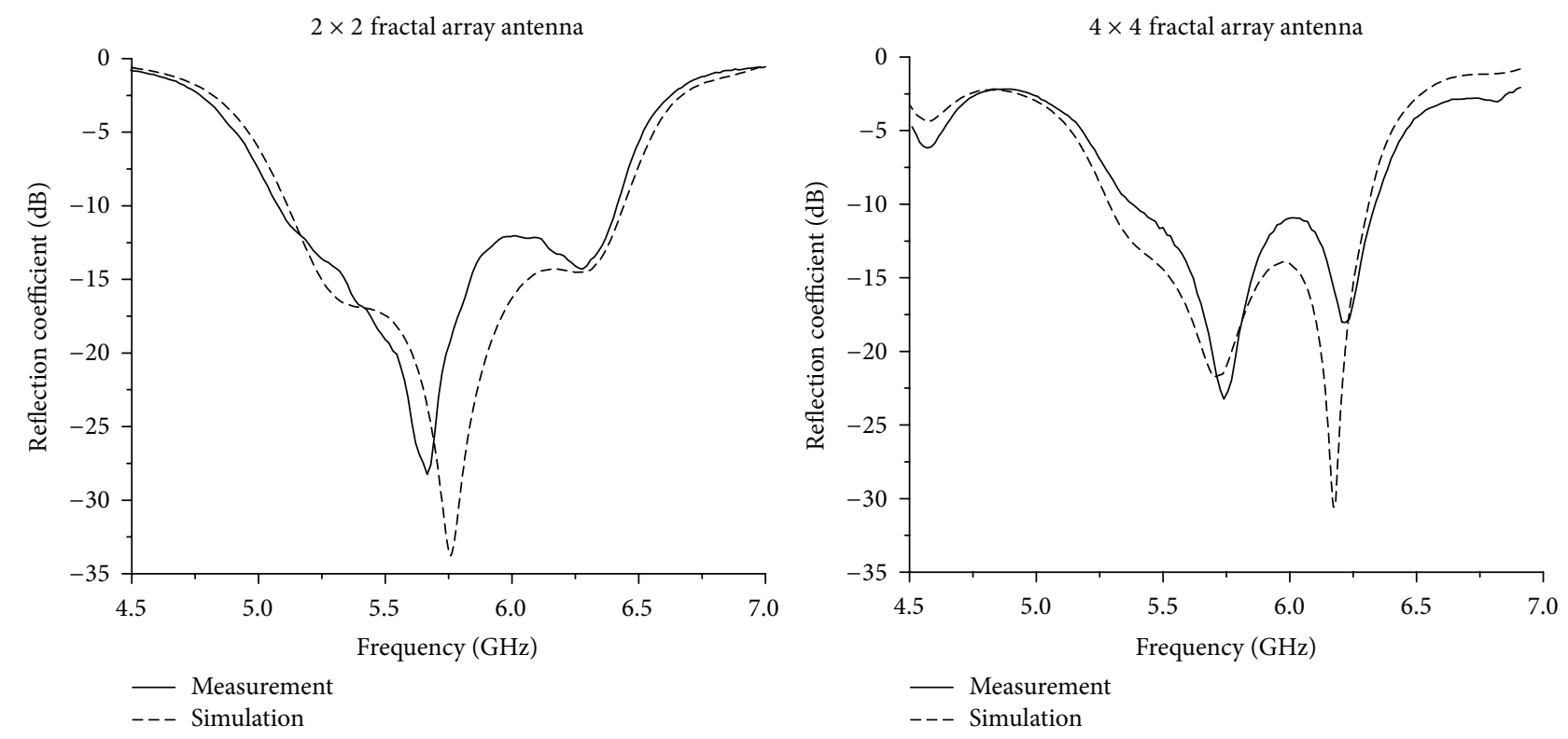

FIGURE 14: The measured and simulated reflection coefficients of the prototype antenna.

is $18.43 \%$ (from $5.32 \mathrm{GHz}$ to $6.40 \mathrm{GHz}$ ), which is much wider than that of square patches antenna array introduced previously.

\section{Experimental Results}

Two prototype antennas with $2 \times 2$ and $4 \times 4$ radiations elements, respectively, have been fabricated and measured, which are shown in Figure 13. Some glass sticks with a diameter of $5 \mathrm{~mm}$ are used for propping them up.

Figure 14 is the comparison of the measured and reflection coefficient of the prototype antennas, respectively.

The measured and simulated results are in good agreement. From the measurement, the $S_{11}<-10 \mathrm{~dB}$ impedance bandwidth of the antenna is about $23.49 \%$ (from $5.07 \mathrm{GHz}$ to $6.42 \mathrm{GHz}$ ) for $2 \times 2$ fractal array antenna and $18.19 \%$ (from $5.34 \mathrm{GHz}$ to $6.41 \mathrm{GHz}$ ) for $4 \times 4$ fractal array antenna, respectively. At its working frequency of $5.8 \mathrm{GHz}$, the antenna has an input reflection coefficient of $-16.95 \mathrm{~dB}$ and $-18.81 \mathrm{~dB}$, respectively, which estimates that a good impedance match has been achieved. Figures 15 and 16 depict the simulated and the measured radiation patterns at different frequencies within the effective frequency band.

\section{Conclusion}

A novel Giuseppe Peano fractal antenna array is presented. Structural parameters of the proposed antenna are optimized by a parallel GA to achieve both high gain and wideband properties over a desirable frequency band with the center of $5.8 \mathrm{GHz}$. Two prototype antennas were fabricated and measured. The measurement results and the simulation results agree well and show that the optimized antenna array possess some encouraging properties. 

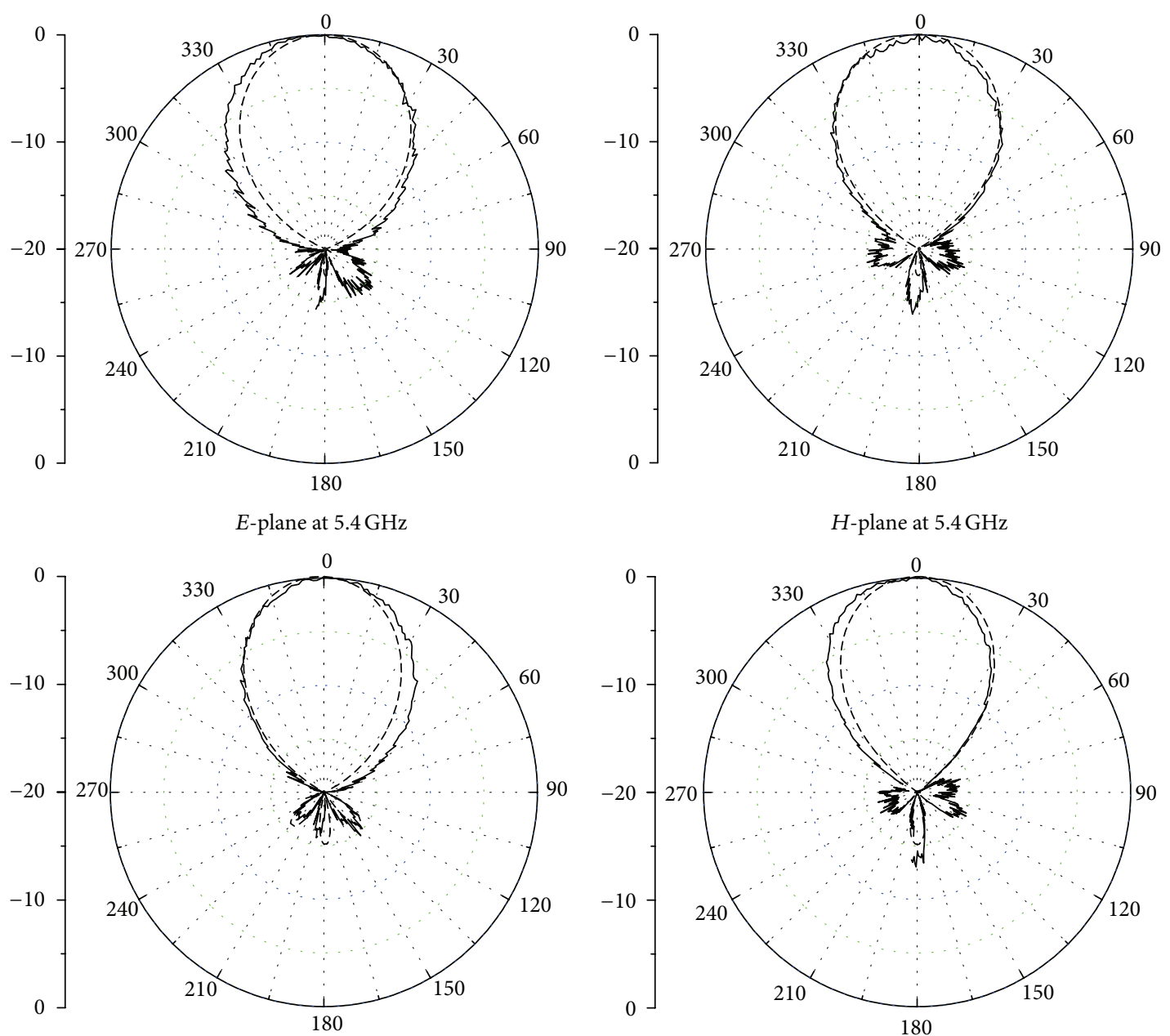

E-plane at $5.8 \mathrm{GHz}$

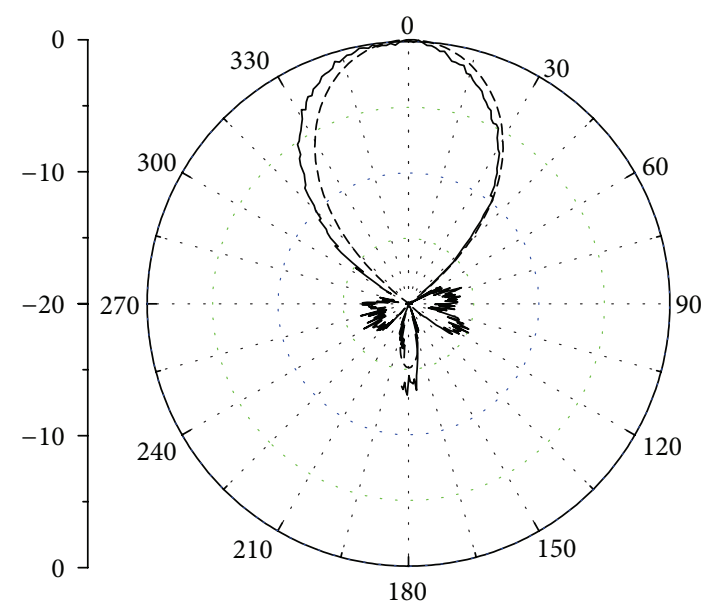

$\mathrm{H}$-plane at $5.8 \mathrm{GHz}$
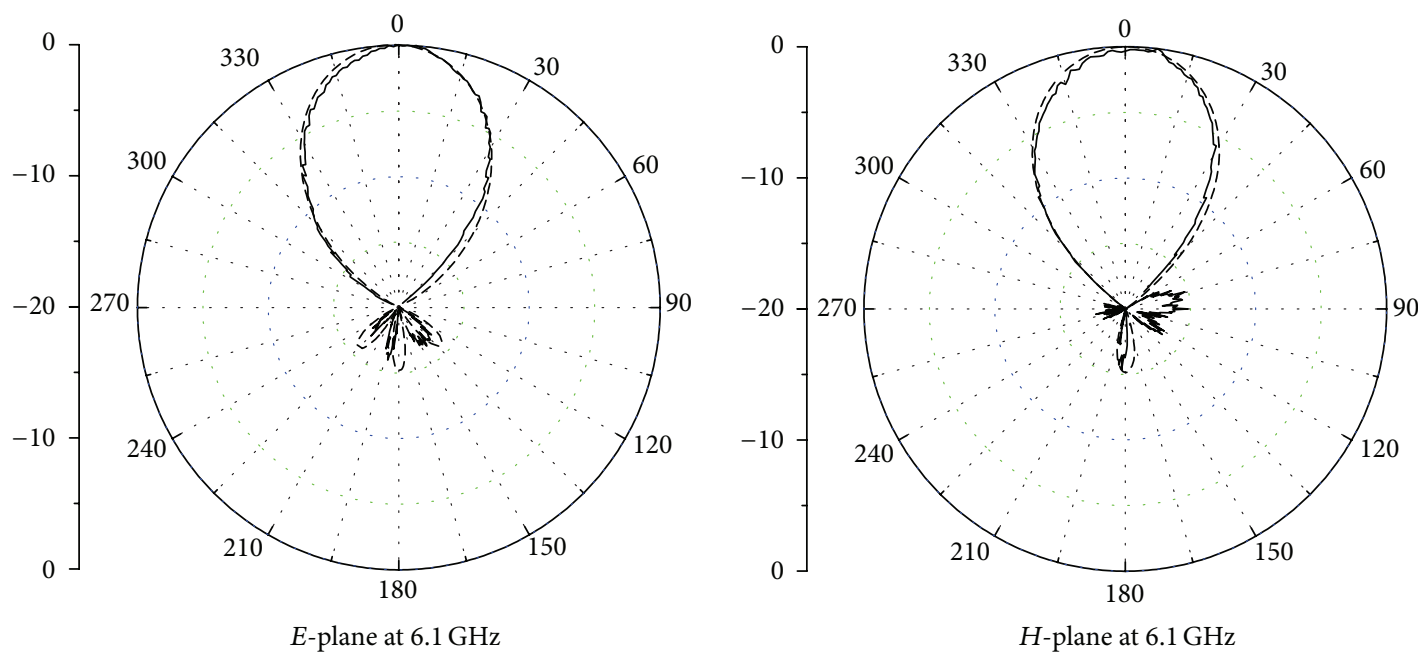

- Measured

- Measured

--_ Simulated

FIGURE 15: Measured and simulated radiation patterns on the $E$-plane and the $H$-plane at different frequencies of the $2 \times 2$ fractal antenna array. 

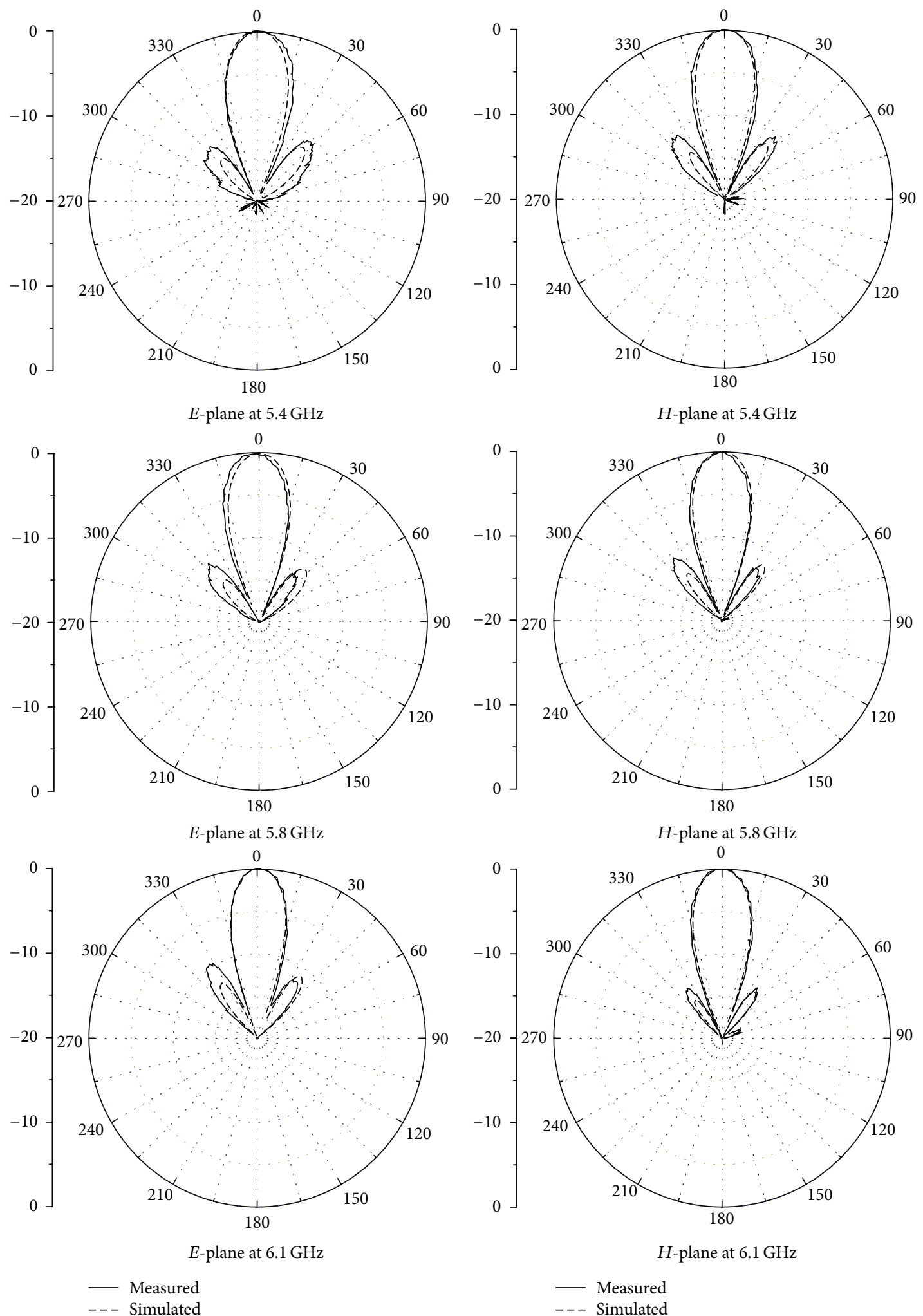

FIGURE 16: Measured and simulated radiation patterns on the $E$-plane and the $H$-plane at different frequencies of the $4 \times 4$ fractal antenna array. 
By comparing the proposed antenna with the square patches one, the important conclusions resulting from this study are as follows.

(1) The Giuseppe Peano fractal configuration provides extremely high flexibility to achieve broadband performance while maintaining higher average aperture efficiency in the operating frequency band. Fractal proportion can be selected according to design requirements; for example, if the impedance bandwidth is a major consideration in design, the fractal proportion $n$ close to 3.5 is comparatively suitable; if the design requires making full use of the high aperture efficiency to maintain the high directivity over the bandwidth, the value $n$ approximating 4 is more reasonable.

(2) In the case of the same number of array elements and the working frequency, the Giuseppe Peano fractal antenna array can more effectively reduce the required aperture area (reduce 51\%) than the traditional square patches antenna array. As the iteration of fractal geometry increases, its resonance frequency decreases; this may lead to an effective miniaturization of antenna. At the same time, the radiation pattern is essentially unchanged.

(3) Although the element number of fractal antenna array is four times that in square antenna, the impedance bandwidth for $S_{11}<-10 \mathrm{~dB}$ is $18.43 \%$ (from $5.32 \mathrm{GHz}$ to $6.40 \mathrm{GHz}$ ), which is still much wider than that of square array antennas introduced previously (which is about $14.02 \%$ from $5.37 \mathrm{GHz}$ to $6.18 \mathrm{GHz}$ ). This clearly showed that the introduction of fractal radiation unit can reduce the mutual coupling between the antenna elements.

Given the conclusion above, the merits of wideband and high aperture efficiency make the proposed antenna a good candidate for various applications.

\section{Conflict of Interests}

The authors declare that there is no conflict of interests regarding the publication of this paper.

\section{References}

[1] D. M. Pozar, "Microstrip antennas," Proceedings of the IEEE, vol. 80, no. 1, pp. 79-91, 1992.

[2] L. Xiuping, A. Yi, X. Xiaowen, and L. Xin, "Design of multilayer microstrip antenna and arrays," Journal of Electronics and Information Technology, vol. 24, no. 8, 2002.

[3] K. Ghorbani and R. B. Waterhouse, "Dual polarized wideband aperture stacked patch antennas," IEEE Transactions on Antennas and Propagation, vol. 52, no. 8, pp. 2171-2175, 2004.

[4] K. L. Chung and A. S. Mohan, "A circularly polarized stacked electromagnetically coupled patch antenna," IEEE Transactions on Antennas and Propagation, vol. 52, no. 5, pp. 1365-1369, 2004.

[5] A. B. Nandgaonkar and S. B. Deosarkar, "Design of high gain two-layer electromagnetically coupled patch antenna in the ISM band," in 2007 International Conference on Electromagnetics in Advanced Applications (ICEAA '07), pp. 547-550, Torino, Italy, September 2007.

[6] J. P. Gianvittorio and Y. Rahmat-Samii, "Fractal antennas: a novel antenna miniaturization technique, and applications," IEEE Antennas and Propagation Magazine, vol. 44, no. 1, pp. 2036, 2002.

[7] D. H. Werner and S. Ganguly, "An overview of fractal antenna engineering research," IEEE Antennas and Propagation Magazine, vol. 45, no. 1, pp. 38-57, 2003.

[8] H. Parikh, S. Pandey, and K. Modh, "Wideband and high gain stacked microstrip antenna for Ku band application," in Proceedings of the Nirma University International Conference on Engineering (NUiCONE '12), pp. 1-5, 2012.

[9] W. Yang, H. Wang, W. Che, and J. A. Wang, "Wideband and high-gain edge-fed patch antenna and array using artificial magnetic conductor structures," IEEE Antennas and Propagation Letters, vol. 12, pp. 769-772, 2013.

[10] P. Y. Lau, K. K. O. Yung, and Z. N. Chen, "A wideband high gain double EBG reflector antenna," in Proceedings of the 8th International Conference on Information, Communications and Signal Processing (ICICS '11), pp. 1-4, Singapore, December 2011.

[11] X. Chen, K. Huang, and X.-B. Xu, "Automated design of a threedimensional fishbone antenna using parallel genetic algorithm and NEC," IEEE Antennas and Wireless Propagation Letters, vol. 4, no. 1, pp. 425-428, 2005.

[12] X. Chen, K. Huang, and X. B. Xu, "Microwave imaging of buried inhomogeneous objects using parallel genetic algorithm combined with FDTD method," Progress in Electromagnetics Research, vol. 53, pp. 283-298.

[13] S. Edelberg and A. A. Oliner, "Mutual coupling effects in large antenna arrays," IRE Transactions on Antennas and Propagation, vol. 8, no. 3, pp. 286-297, 1960.

[14] D. M. Pozar, "Input impedance and mutual coupling of rectangular microstrip antennas," IEEE Transactions on Antennas and Propagation, vol. 30, no. 6, pp. 1191-1196, 1982. 

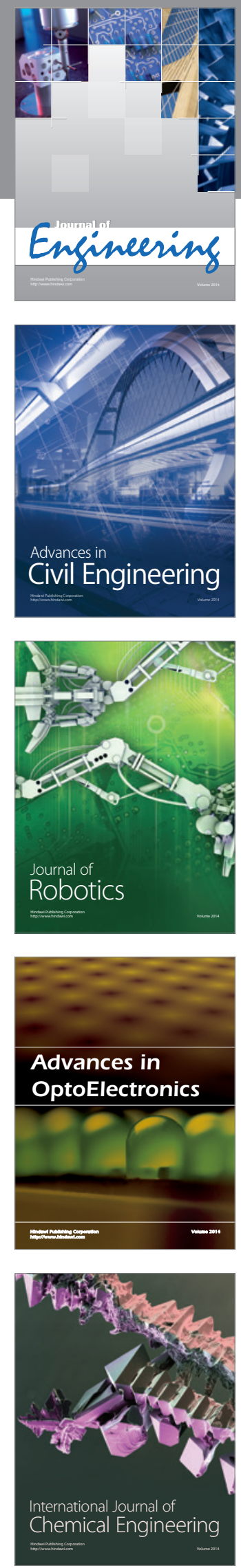

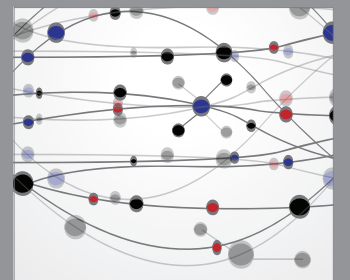

The Scientific World Journal
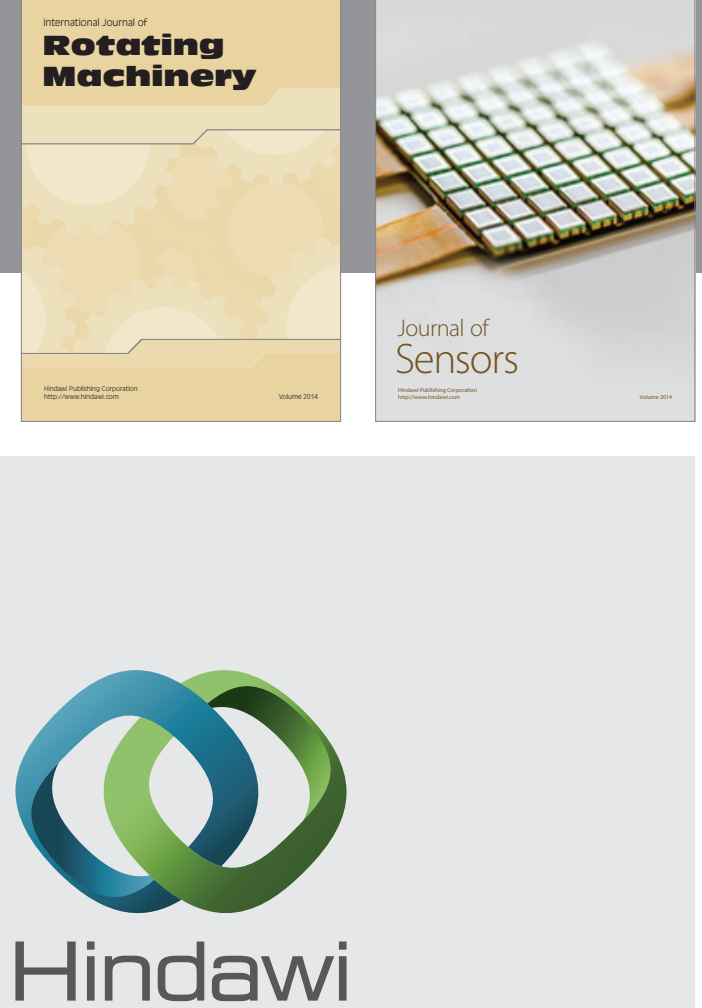

Submit your manuscripts at http://www.hindawi.com
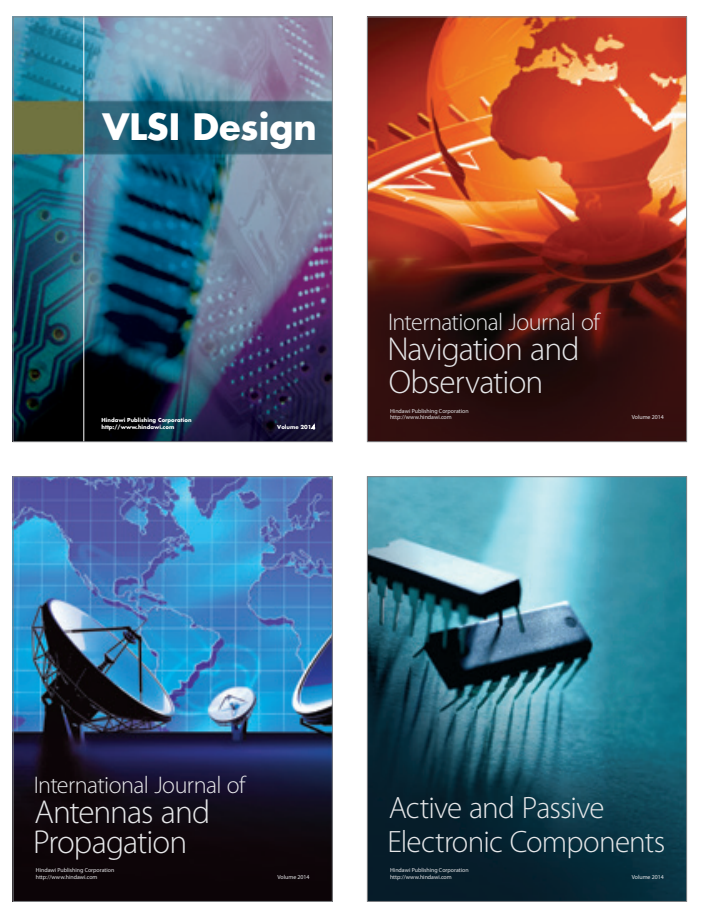
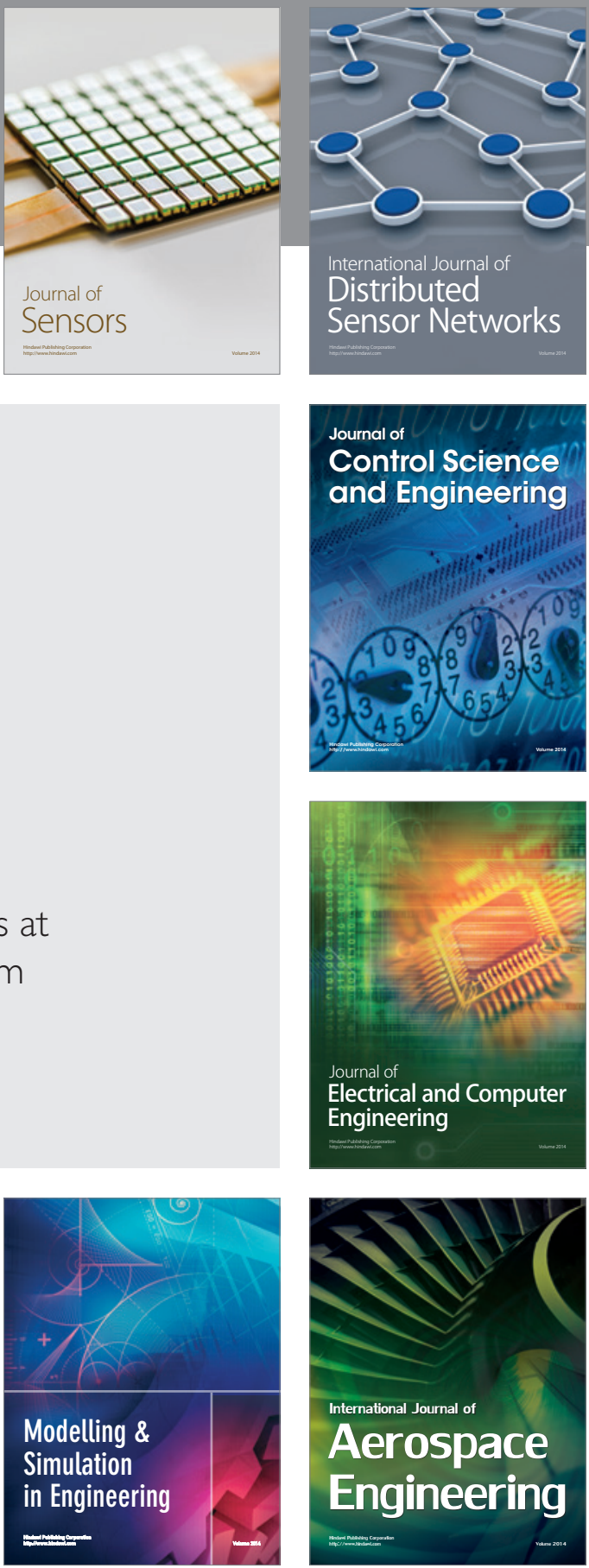

Journal of

Control Science

and Engineering
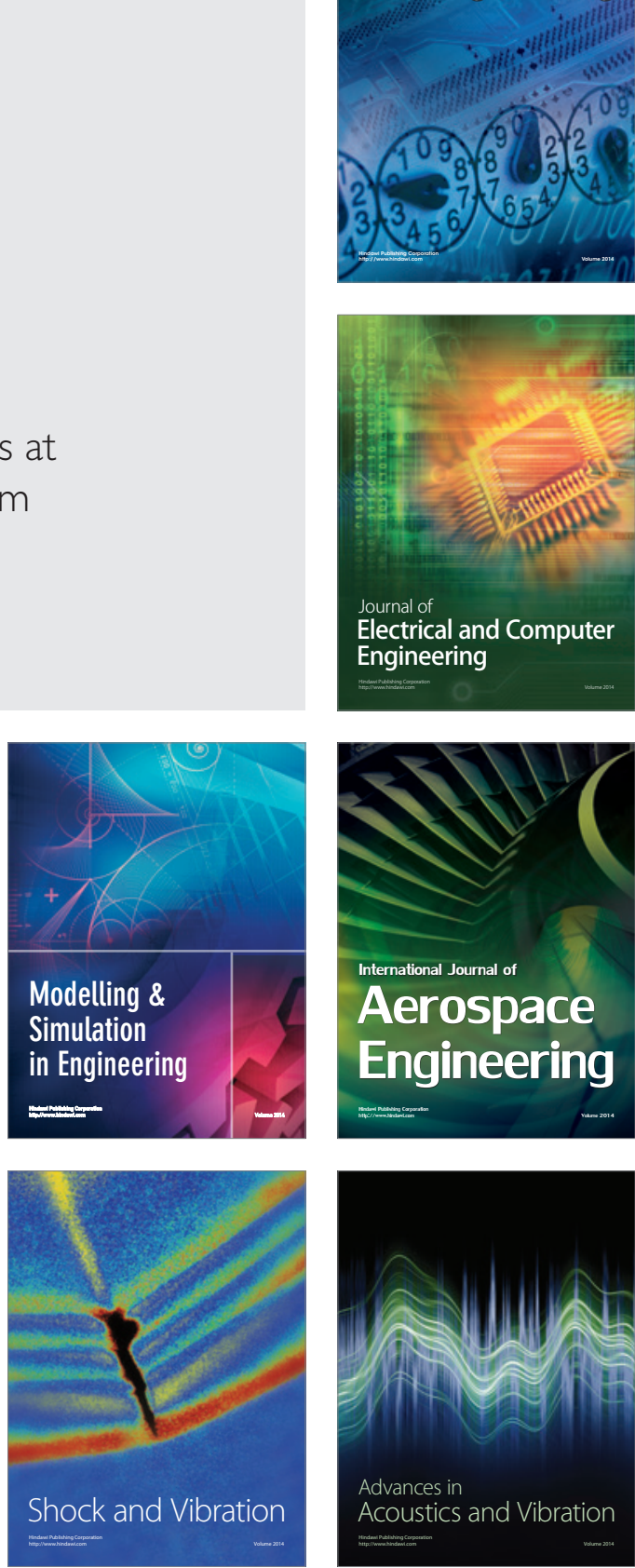